\title{
NEUROENDOCRINE AND BEHAVIORAL RESPONSE TO AMPHETAMINE CHALLENGE AFTER EXPOSURE TO AN ORGANOPHOSPHORUS PESTICIDE
}

\section{SŁAWOMIR GRALEWICZ, PIOTR LUTZ, RADOSŁAW ŚWIERCZ, ZOFIA GRZELIŃSKA, and DOROTA WIADERNA}

Nofer Institute of Occupational Medicine, Łódź, Poland

Department of Toxicology and Carcinogenesis

\begin{abstract}
Objectives: Exposure to various stressors is known to result in sensitization to psychostimulants, a state related to the psychostimulant dependence and addiction. It has been shown in some studies that the rise in corticosterone (CORT) concentration is indispensable for both the induction and the expression of behavioral sensitization. Therefore, it might be suspected that behavioral hyposensitivity to amphetamine (AMPH) is somehow related to a reduced CORT response to the psychostimulant subsequent to the chlorphenvinphos (CVP) intoxication. Materials and Methods: The male adult Wistar rats received single i.p. injections of CVP at the doses $0.5,1.0$ or $3.0 \mathrm{mg} / \mathrm{kg}$ b.w., or pure corn oil. CORT concentration was determined in samples of blood drawn from the tail vein before and then 30, 60, $180 \mathrm{~min}$ and $24 \mathrm{~h}$ after injection. The other rats were divided into two groups and tested, three weeks after the CVP injection for the effect of AMPH $(0.5 \mathrm{mg} / \mathrm{kg}$ b.w. i.p. $)$ on the serum CORT concentration. In addition, behavioral sensitivity to AMPH was assessed by measuring locomotor activity of the animals in an open-field. Results: 1) The stressor property of CVP was confirmed. The injection resulted in up to tenfold increase in the serum CORT concentration. The magnitude and duration of this response were dose-related. 2) Three weeks after the CVP exposure, the CORT response to AMPH was significantly increased. 3) The behavioral response to the psychostimulant, i.e. augmented locomotion, was significantly reduced compared to the control. Conclusions: The results confirm that CVP exposure causes behavioral hyposensitivity to AMPH. This effect, however, could not be ascribed to a diminished CORT response.
\end{abstract}

Key words:

Amphetamine, Chlorphenvinphos, Corticosterone, Behavior, Rats

\section{INTRODUCTION}

Exposure to stressors may result in serious health consequences which include depressive states, posttraumatic stress disorder (PTSD), somatoform disorders, psychosomatic diseases, and promote development of drug dependencies and addiction [1-5]. Deregulation of the hypothalamo-pituitary-adrenal axis (HPA axis) control is assumed as the likely cause of these effects [6-9].
In some laboratory animal studies, a long-term increase in the HPA axis reactivity was observed after a stressful experience as suggested by a stronger nerohumoral response, i.e. increase in the blood glucocorticoid, corticosterone (CORT), and adrenocorticothropic hormone (ACTH) levels to subsequent stress [10-12]. In several studies, however, an opposite effect was noted: a reduced or shortened CORT response to stressors indicating a diminished HPA axis reactivity [13-15]. The likely

Received: Dec 1, 2010. Accepted: March 8, 2011.

Reprint requests to: P. Lutz, Department of Toxicology and Carcinogenesis, Nofer Institute of Occupational Medicine, św. Teresy 8, 91-348 Łódź, Poland (e-mail: astra@imp.lodz.pl). 
causes of these discrepancies have been discussed in a recent review [16].

A number of chemicals, many of which are in common use and are manufactured in large quantities, are stressors. They include organophosphorus pesticides (OPs) inhibitors of acetylcholinesterase - extensively used in agriculture and households. The stressor activity of these substances is evidenced by exposure-induced somatic and vegetative symptoms as well as strong and hours-long rise in the blood glucocorticoid concentration [17-19]. Some human data indicate that OPs poisoning may result in persistent psychological alterations resembling those in PTSD [20]. According to some authors, disturbed control of the HPA axis is the main cause of PTSD [21].

The present study concerns chlorphenvinphos [(2-chloro1(2,4-dichlorophenyl) vinyl diethyl phosphate - CVP)], a pesticide used in some EU countries for pest control, mainly in greenhouses. CVP is a direct AChE inhibitor. As we have reported earlier, a single exposure of the rat to CVP, even at a moderate dose, makes the animal hyporesponsive behaviorally to amphetamine (AMPH) weeks later [22-23]. Needless to say, AMPH is an indirect dopaminergic agonist and one of the most frequently abused psychostimulants. Exposure to some stressors is known to result in behavioral and neuroendocrine sensitization to AMPH [24-26], a state which, according to some authors, may promote the development of psychostimulant dependence and addiction [27-28]. In the context of this hypothesis, the behavioral hyposensitivity to AMPH after CVP exposure becomes intriguing. It is known that the magnitude of the behavioral AMPH response and the reactivity of the HPA axis are closely related [29-31]. It has also been demonstrated that CORT is necessary for both the development and the expression of behavioral hypersensitivity to AMPH [32-33]. Based on the above, one may presume that the reduced behavioral sensitivity to AMPH observed in our experiments was due to a diminished reactivity of the HPA axis subsequent to the previous CVP exposure. The CORT response, i.e. the stressor-induced rise in the blood CORT concentration is a reliable and accepted index of the HPA axis reactivity. The main purpose of the present experiment was to find out whether and in what way the CORT response to an AMPH test dose was influenced by a prior exposure to CVP.

\section{MATERIALS AND METHODS}

\section{Animals}

Seventy-two outbred male Wistar rats were used in the experiment. The rats were 3-4 months old and weighed 340-360 g at the experiment onset. For four weeks before the experiment and during its course, they were housed in individual polyethylene cages at $22^{\circ} \mathrm{C} \pm 0.5^{\circ} \mathrm{C}$, with a light/dark cycle of 12/12 h (light on at 06:00 h). Standard rat food pellets (Murigran) and tap water were accessible ad libitum. Body weight was measured once a week and before each drug administration. The study design was approved by the Local Ethic Committee in Lódź (Opinion No: $Ł / B D / 370$, Issue date: 2007-06-25).

\section{Chemicals, doses and drug administration procedure}

The following compounds were used: CVP, technical grade, obtained from ORGANIKA-AZOT, Jaworzno, Poland; and AMPH (d-amphetamine sulphate) from SIGMA. CVP was diluted in corn oil, while AMPH was dissolved in physiological saline (Natrium Chloratum $0.9 \%$, POLFA). All solutions were given intraperitoneally at $1.0 \mathrm{ml} / \mathrm{kg}$. The pesticide was administered at doses of $0.5,1.0$ or $3.0 \mathrm{mg} / \mathrm{kg}$ of body weight (b.w.). AMPH was administered at $0.5 \mathrm{mg} / \mathrm{kg}$ b.w. The pesticide and AMPH doses were in the range of doses used in our earlier experiments [23]. In all cases, the injections as well as the collection of blood samples took place outside the animal room. 


\section{Biochemical investigation:}

\section{serum corticosterone (CORT) assays}

In the biochemical part, the serum CORT concentrations were determined in 8 groups of rats ( $\mathrm{n}=5$ in each group) denoted as follows: group $1-$ oil; group $2-0.5$ CVP; group $3-1.0 \mathrm{CVP}$; group $4-3.0 \mathrm{CVP}$; group $5-$ oil/AMPH; group $6-0.5 \mathrm{CVP} / \mathrm{AMPH}$; group 7 - $1.0 \mathrm{CVP} / \mathrm{AMPH}$; group $8-3.0 \mathrm{CVP} / \mathrm{AMPH}$. See Table 1 for group denotation and procedure. The serum CORT concentrations were determined in $200 \mu \mathrm{l}$ samples of blood drawn from the tail vein (the "nick" method) into Eppendorf vials at the following time points: $30 \mathrm{~min}$ before the drug administration (CVP or AMPH) and $30 \mathrm{~min}, 60 \mathrm{~min}, 180 \mathrm{~min}$ and $24 \mathrm{~h}$ after the administration. The samples were left at room temperature until they clotted and then they were centrifuged at $3000 \mathrm{rpm}$. Serum samples (each about $40 \mu \mathrm{l}$ ) were stored at $-70^{\circ} \mathrm{C}$ until the analysis. The CORT concentration was estimated by high performance liquid chromatography (HPLC) using betamethasone as an internal standard [34].

\section{Behavioral investigation: open field behavior}

In the behavioral part of the experiment, the open field locomotion before and after the administration of the AMPH test dose was assessed in four groups of rats pretreated 21 days earlier with oil or CVP at $0.5,1.0$ or $3.0 \mathrm{mg} / \mathrm{kg}$ (Table 2). (Note: Different groups were used in the behavioral and the biochemical part.) A computerized 4-unit set of activity cages (PORFEX Ltd., Białystok, Poland) was used. Each cage $(63 \times 63 \times 40 \mathrm{~cm})$ was equipped with 2 tiers of infrared motion sensors to measure locomotor (walked distance) and exploratory (rears) activities. Detailed description of the apparatus and the testing procedure has been presented in earlier papers [35]. All measurements of the locomotor activity were conducted between 7 a.m. and 2 p.m. The testing comprised two separate 60 min measurements: the preinjection measurement and the postinjection one. After completion of the preinjection measurement, the rat was removed from the activity cage and placed in its own home cage for $8-10 \mathrm{~min}$. During this time the activity cage was cleaned and wiped with wet froth. Then the rat was injected with AMPH and placed again in the open field for the postinjection measurement [33].

\section{Statistical analysis}

A two-way ANOVA (groups x measurements) for repeated measures was employed and the data was analyzed using software Stastistica.pl (NIOM, Poland). When a significant interaction was found, it was

Table 1. Groups and procedure in the biochemical part of the experiment

\begin{tabular}{|c|c|c|c|}
\hline $\begin{array}{l}\text { Group } \\
\text { number }\end{array}$ & Group denotation & $\begin{array}{c}\text { Animals treated } \\
\mathrm{n}\end{array}$ & $\begin{array}{l}\text { Animal description and time } \\
\text { of blood samples collection }\end{array}$ \\
\hline 1 & oil & 5 & \multirow{4}{*}{$\begin{array}{l}\text { Non-pretreated (naive) rats. Blood samples collected } 30 \mathrm{~min} \text { before } \\
\text { and } 30 \mathrm{~min}, 60 \mathrm{~min}, 180 \mathrm{~min} \text { and } 24 \mathrm{~h} \text { after i.p. injection of oil (group 1) } \\
\text { or CVP } 0.5 \mathrm{mg} / \mathrm{kg} \text { (group 2), } 1.0 \mathrm{mg} / \mathrm{kg} \text { (group 3) or } 3.0 \mathrm{mg} / \mathrm{kg} \text { (group 4) }\end{array}$} \\
\hline 2 & $0.5 \mathrm{CVP}$ & 5 & \\
\hline 3 & $1.0 \mathrm{CVP}$ & 5 & \\
\hline 4 & $3.0 \mathrm{CVP}$ & 5 & \\
\hline 5 & oil/AMPH & 5 & \multirow{4}{*}{$\begin{array}{l}\text { Rats pretreated with oil (group 5) or } 0.5,1.0 \text {, or } 3.0 \mathrm{mg} / \mathrm{kg} \mathrm{CVP} \\
\text { (group 6, } 7 \text { and 8, respectively) } 21 \text { days before i.p. administration } \\
\text { of } 0.5 \mathrm{mg} / \mathrm{kg} \text { of AMPH. Blood samples collected } 30 \text { min before } \\
\text { and } 30 \mathrm{~min}, 60 \mathrm{~min}, 180 \mathrm{~min} \text { and } 24 \mathrm{~h} \text { after AMPH injection }\end{array}$} \\
\hline 6 & $0.5 \mathrm{CVP} / \mathrm{AMPH}$ & 5 & \\
\hline 7 & $1.0 \mathrm{CVP} / \mathrm{AMPH}$ & 5 & \\
\hline 8 & $3.0 \mathrm{CVP} / \mathrm{AMPH}$ & 5 & \\
\hline
\end{tabular}

Oil — vehicle; CVP — chlorphenvinphos; AMPH — amphetamine. 
Table 2. Groups and procedure in the behavioral part of the experiment

\begin{tabular}{llcl}
\hline $\begin{array}{c}\text { Group } \\
\text { number }\end{array}$ & Group denotation & $\begin{array}{c}\text { Animals treated } \\
\mathrm{n}\end{array}$ & \multicolumn{1}{c}{ Experimental procedure in groups } \\
\hline 1 & oil/AMPH & 8 & Rats pretreated with oil (group 1) or 0.5, 1.0, or 3.0 mg/kg CVP \\
2 & $0.5 \mathrm{CVP} / \mathrm{AMPH}$ & 8 & (group 6, 7 and 8, respectively) 21 days before i.p. administration \\
3 & $1.0 \mathrm{CVP} / \mathrm{AMPH}$ & 8 & of 0.5 mg/kg of AMPH. Open-field activity measured 60 min before \\
4 & $3.0 \mathrm{CVP} / \mathrm{AMPH}$ & 8 & and 60 min after AMPH administration \\
\hline
\end{tabular}

Abbreviations as in Table 1.

followed by one-way ANOVA and Tukey's test for pairwise comparisons [36]. Differences were regarded as significant when the probability of the null hypothesis was $5 \%$ or less.

\section{RESULTS}

\section{Biochemical part: serum CORT determinations}

Effect of CVP on the serum CORT concentration

Figure 1 illustrates the effect of CVP administration on the serum CORT concentration. The two-way ANOVA showed a significant effect of both main factors groups: $\mathrm{F}(3.16)=125.55, \mathrm{p}<0.0001$, measurements: $\mathrm{F}(1.16)=43.72, \mathrm{p}<0.0001$ and significant groups $\mathrm{x}$ measurements interaction: $\mathrm{F}(3.16)=125.33, \mathrm{p}<0.0001$. The groups did not differ in the preinjection CORT values. After the injection, the serum CORT concentration increased in all groups. In the oil group, the rise was relatively small and the differences between successive measurements were not significant. In groups injected with CVP, the magnitude of the postinjection CORT response was larger and evidently dose-dependent; it was strongest and most persistent in the 3.0 CVP group and almost negligible in the 0.5 CVP group. Comparisons between the groups at successive time points revealed that, compared to the OIL group, the serum CORT level was significantly elevated at $180 \mathrm{~min}$ after the CVP injection in the 1.0 CVP group and at all postinjection time points in the $3.0 \mathrm{CVP}$ group.
Effect of the CVP pretreatment on the CORT response to the AMPH challenge Figure 2 illustrates the effect of the CVP pretreatment on the CORT response to the AMPH challenge 21 days after the pretreatment. In all groups, the AMPH administration resulted in an elevation of the serum CORT concentration. This effect was most pronounced $60 \mathrm{~min}$ after the injection. The outcome of the main factors, as well as the interaction, were statistically significant - group: $\mathrm{F}(3.16)=6.66, \mathrm{p}<0.005$; measurement: $\mathrm{F}(1.16)=51.39, \mathrm{p}<0.001$; interaction: $\mathrm{F}(3.16)=44.53, \mathrm{p}<0.0001$. Detailed comparisons confirmed that $60 \mathrm{~min}$ after injection, the rise in the serum CORT concentrations was significant in all groups. The groups, however, differed markedly in scope of the magnitude of this effect; in group 1.0 CVP/AMPH, and 3.0 CVP/AMPH, the serum CORT concentration was significantly higher than in the oil-AMPH and the 0.5 CVP group.

\section{Behavioral part: Effect of the CVP pretreatment on the locomotor response to AMPH}

The differences between the subjects in the preinjection as well as the postinjection measurements of the exploratory activity were very high in each group. Thus, the reliability of the statistical comparisons was questionable and the data concerning this measure has been omitted. As for the locomotor activity measurements, the distances recorded during the 60 -min periods were 

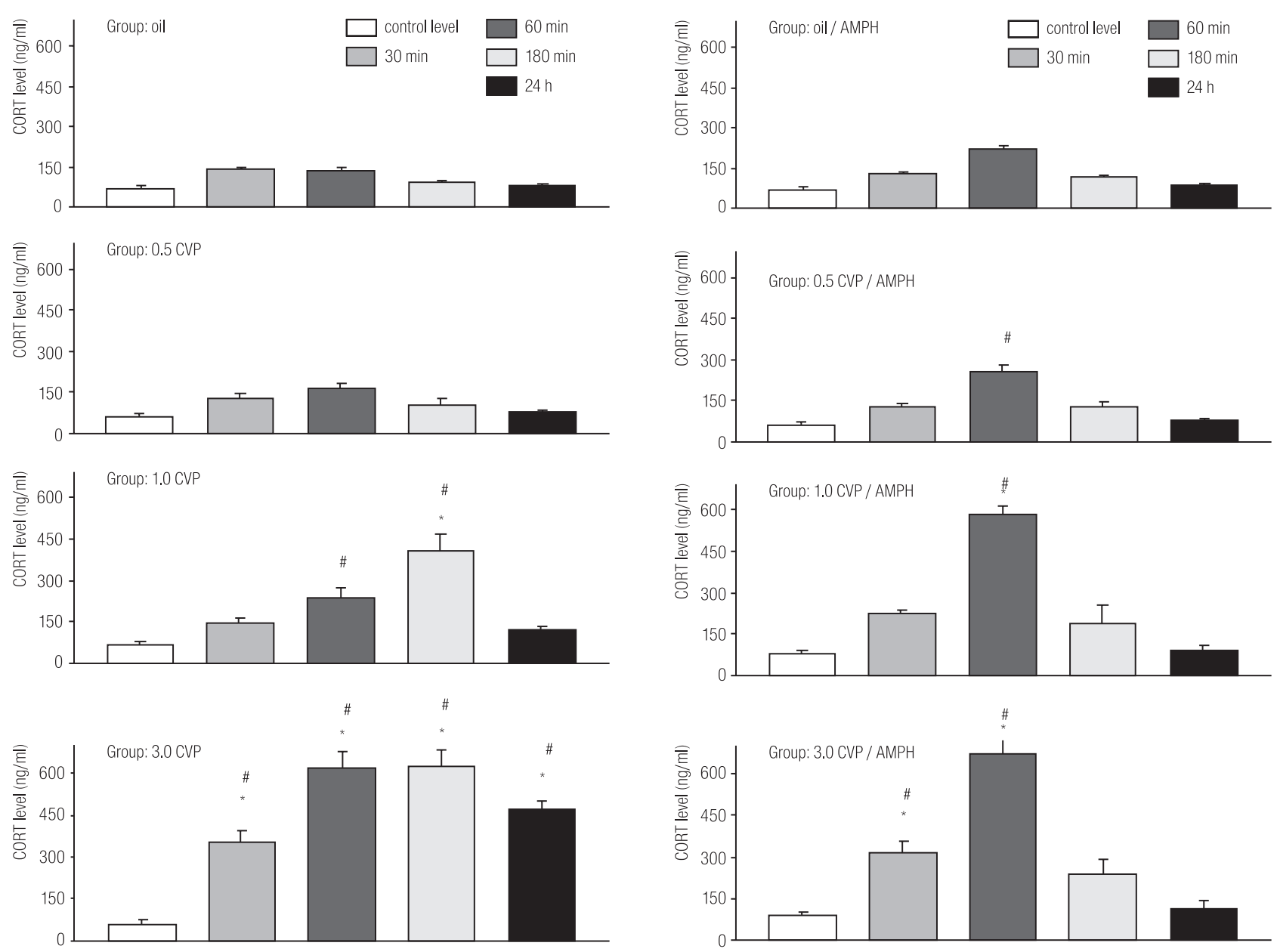

The bars represent serum CORT concentrations (means and SEM) before (white bar) and $30 \mathrm{~min}$ (striped bar), $60 \mathrm{~min}$ (grated bar), $180 \mathrm{~min}$ (dotted bar) and $24 \mathrm{~h}$ (black bar) after the CVP injection. Statistics ANOVA: group effects: $\mathrm{F}(3.16)=125.55, \mathrm{p}=0.0000$; measurement effects: $\mathrm{F}(1.16)=43.72, \mathrm{p}=0.0000$; interaction: $\mathrm{F}(3.16)=125.33, \mathrm{p}=0.0000$.

$\# \mathrm{p}<0.05$ - compared to control level in the same group. $* \mathrm{p}<0.05$ - compared to oil (control) group in the same measurements.

Fig. 1. Diagrams illustrating changes in the serum CORT concentration following a single i.p. injection of CVP at doses: oil group (control), $0.5 \mathrm{mg} / \mathrm{kg}$ (0.5 CVP group), $1.0 \mathrm{mg} / \mathrm{kg}$ (1.0 CVP group), or $3.0 \mathrm{mg} / \mathrm{kg}$ (3.0 CVP group).

summed into two bins representing the preinjection and the postinjection locomotion, respectively (Figure 3). The analysis revealed that the effects of both main

The bars represent serum CORT concentrations (means and SEM) before (white bar) and $30 \mathrm{~min}$ (striped bar), $60 \mathrm{~min}$ (grated bar), $180 \mathrm{~min}$ (dotted bar) and $24 \mathrm{~h}$ (black bar) after the AMPH injection. Statistics: ANOVA: group effects: $\mathrm{F}(3.16)=6.66, \mathrm{p}=0.0039$; measurement effects: $\mathrm{F}(1.16)=51.39, \mathrm{p}=0.0000$; interaction: $\mathrm{F}(3.16)=44.53, \mathrm{p}=0.0000$.

$\# \mathrm{p}<0.05$ - compared to control level in the same group. $* \mathrm{p}<0.05$ - compared to oil/AMPH (control) group in the same measurements.

Fig. 2. Diagrams illustrating changes in the serum CORT concentration in response to the AMPH test dose $(0.5 \mathrm{mg} / \mathrm{kg})$ administered on day 21 after a single injection of CVP at doses: control (oil/AMPH group), $0.5 \mathrm{mg} / \mathrm{kg}$ (0.5 CVP/AMPH group), $1.0 \mathrm{mg} / \mathrm{kg}$ (1.0 CVP/AMPH group), or $3.0 \mathrm{mg} / \mathrm{kg}$ (3.0 CVP/AMPH group).

factors as well as the interaction were significant group effect: $\mathrm{F}(3.28)=7.78, \mathrm{p}<0.0001$; measurement effect: $\mathrm{F}(1.28)=46.54, \mathrm{p}<0.0001)$; interaction: 

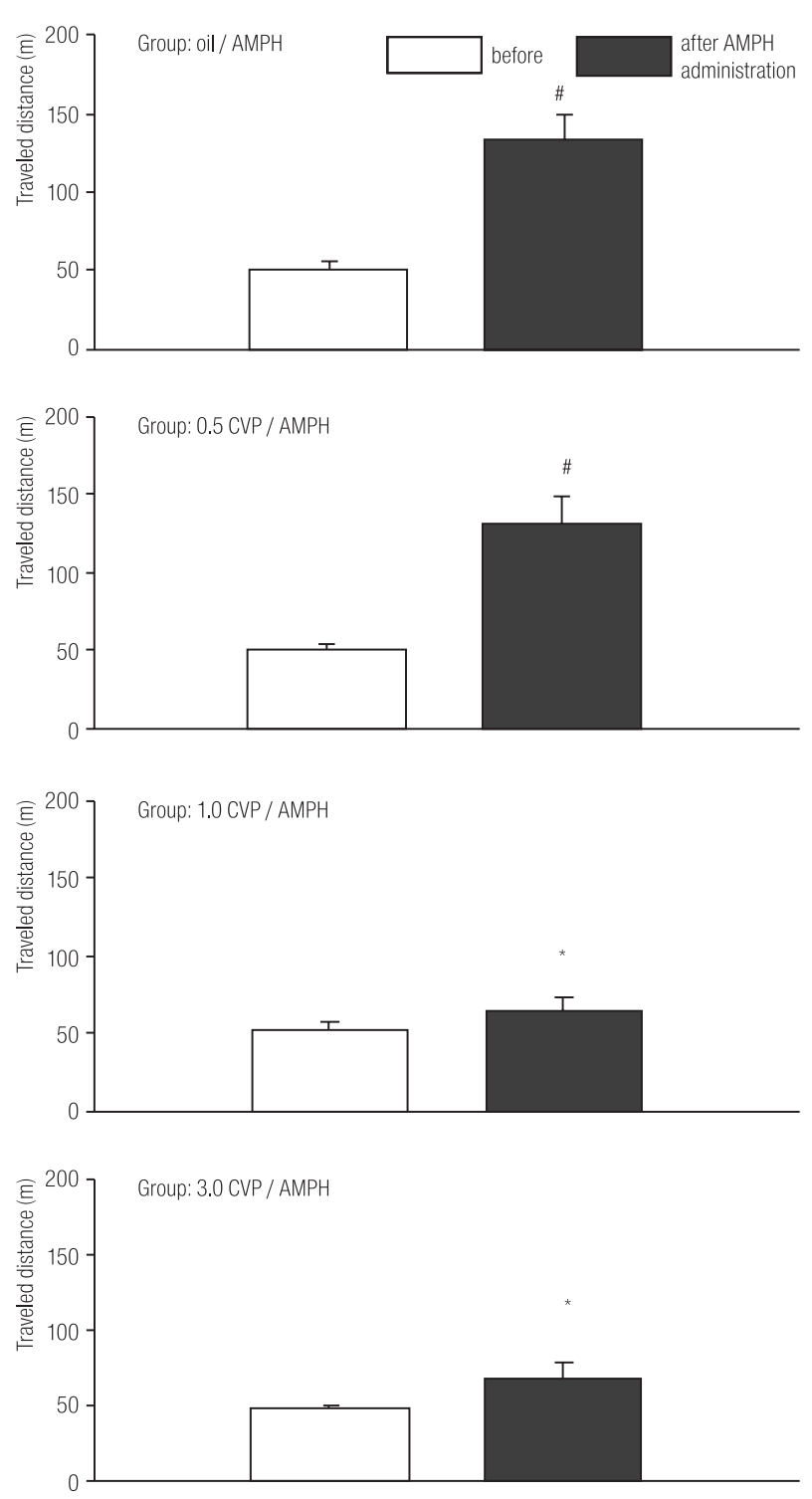

The bars represent the distances (means and SEM) traveled during $60 \mathrm{~min}$ before (white bar) and $60 \mathrm{~min}$ after (black bar) AMPH administration.

Statistics ANOVA: group effects: $\mathrm{F}(3.28)=7.78, \mathrm{p}=0.0006$;

measurement effects: $\mathrm{F}(1.28)=46.54, \mathrm{p}=0.0000$; interaction: $\mathrm{F}(3.28)=65.01, \mathrm{p}=0.0000$.

$\# \mathrm{p}<0.05$ - compared to control level in the same group.

$* \mathrm{p}<0.05-$ compared to oil/AMPH (control) group in the same measurements.

Fig. 3. Diagrams illustrating the change in the distance traveled in the open field by rats given AMPH test dose $(0.5 \mathrm{mg} / \mathrm{kg})$ on day 21 after a single injection of CVP at doses: $0.0 \mathrm{mg} / \mathrm{kg}$ (oil/ AMPH group), $0.5 \mathrm{mg} / \mathrm{kg}$ (0.5 CVP/AMPH group), $1.0 \mathrm{mg} / \mathrm{kg}$ (1.0 CVP/AMPH group), or $3.0 \mathrm{mg} / \mathrm{kg}$ (3.0 CVP/AMPH group).
$\mathrm{F}(3.28)=65.01, \mathrm{p}<0.0001)$. The groups did not differ significantly in their preinjection measurements. However, the postinjection measurements appeared significantly larger in groups oil/AMPH and $0.5 \mathrm{CVP} / \mathrm{AMPH}$ than in the remaining two groups. Comparisons between the measurements within each group showed that in the oil/AMPH and 0.5 CVP/AMPH groups, the locomotor activity after AMPH administration was significantly increased compared to the control (preinjection) measurement. In groups 1.0 CVP-AMPH and 3.0 CVP-AMPH, the preinjection and the postinjection measurements did not differ significantly.

\section{DISCUSSION}

Summing up, the results of the present experiment are as follows. CVP administration induces stress response as evidenced by the increase in the serum CORT concentration. The magnitude of the CORT response (its amplitude and duration) correlates positively with the CVP dose. In the CVP-treated animals, the behavioral response to the AMPH challenge is weakened (practically non-existent), but the neuroendocrine CORT response is significantly stronger than in the control rats.

In respect of the CORT response, the results of the present study are not surprising. The efficiency of CVP in provoking this response has been documented in some earlier studies [18], including our own [19]. In the context of the present work, two issues are worth stressing. First is the threshold CVP dose for the CORT response which as may be judged from the data - is close to $1.0 \mathrm{mg} / \mathrm{kg}$. According to our earlier observations, $1.0 \mathrm{mg} / \mathrm{kg}$ CVP given intraperitoneally results in about $50 \%$ reduction of the erythrocyte AChE activity [37]. The second issue concerns the dynamics of this response; its maximum is reached about $3 \mathrm{~h}$ after the pesticide administration, i.e. at nearly the same time as the maximum of the AChE inhibition [37]. 
As regards the behavioral response to the AMPH challenge, the present results are concordant with our earlier observations which showed that in rats exposed to CVP this response, i.e. increased locomotion, was weakened [22]. Noteworthy, as it appears from the present results, the threshold CVP dose for induction of this effect is somewhere between 0.5 and $1.0 \mathrm{mg} / \mathrm{kg}$, i.e. close to the threshold dose for the CORT response.

Unlike the behavioral effect of the CVP exposure, the neuroendocrine one, i.e. the augmented CORT response to the AMPH challenge, was not expected. Firstly, the results obtained in some laboratories suggested reduced reactivity of the HPA axis following exposure to a stressor. According to Armario et al., such an effect is related to homologous stressors only [16]. There are some reports, however, showing that the HPA response to heterologous stressors may also be reduced during the days following a stressful experience [13]. Diminished HPA response was also observed after a systemic administration of CORT at a high dose [13], which indicates that this effect could be linked to the stressrelated increase in the CORT concentration. Reduced reactivity of the HPA axis long time after a stressful experience was also suggested by the results of our earlier studies. We found that in rats subjected to a single 20 min series of unavoidable footshocks two weeks before a single CVP administration (1.0 $\mathrm{mg} / \mathrm{kg}$ i.p.) the pesticide-induced rise in the serum CORT concentration was markedly diminished [19]. In the light of these observations the expectation of a reduced CORT response to AMPH in CVP-treated rats was not unreasonable. The obtained results, however, show clearly that a single CVP administration, even at a relatively low dose, results in an augmented CORT response to AMPH weeks later. This means that the behavioral hyporeactivity to AMPH [22], and the present results as well as the reduced susceptibility to develop behavioral sensitization upon a repeated AMPH treatment of the CVP pretreated rats [23] could not have resulted from a reduced reactivity of the HPA axis. Moreover, it appears that, as far as the CORT response is concerned, the long-term effect of the single CVP exposure is similar to the effect of a single AMPH exposure which is known to result in an augmented reactivity of the HPA axis [38]. Why then, the longterm behavioral effects are contrasting? It seems likely that this disparity may stem from the differences in the acute behavioral effects and emotional states induced by these substances, i.e. augmented locomotion and exploration in case of AMPH and immobility in crouching fearful posture in case of CVP. As a result, different behavioral and emotional systems may be sensitized; the "stop" system in case of CVP, and the "go" system in case of AMPH. The behavioral tendency acquired in this way may compete with, or augment, the response to the AMPH challenge weeks later.

Notwithstanding the validity of the above explanation, the results of the present experiment show clearly that exposure to CVP, while making the animal hyporesponsive to AMPH on the behavioral level, makes it hypersensitive to the psychostimulant, and possibly to other stressors, on the neurohumoral level: it sensitizes the HPA axis. Owing to such an action, exposure to CVP (and possibly other OPs) may be a suspected promoter of health problems, known to be related to increased reactivity of the HPA axis.

\section{ACKNOWLEDGMENTS}

This study was supported by the Nofer Institute of Occupational Medicine in Łódź. The skilful technical assistance of Mr. Krzysztof Mader is gratefully acknowledged.

\section{REFERENCES}

1. Gordon HW. Early environmental stress and biological vulnerability to drug abuse. Psychoneuroendocrinology 2002;27:115-26. 2. Goeders NE. The impact of stress on addiction. Eur Neuropsychopharmacol 2003;13:435-41.

3. Swaab DF, Bao AM, Lucassen PJ. The stress system in the human brain in depression and neurodegeneration. Ageing Res Rev 2005;4:141-94. 
4. Sinha R. Chronic stress, drug use, and vulnerability to addiction. Ann NY Acad Sci 2008;1141:105-30.

5. McFarlane AC. The long-term cost of traumatic stress: intertwined physical and psychological consequences. World Psychiatry 2010;9:5-10.

6. Kreek MJ, Koob GF. Drug dependence: stress and dysregulation of brain reward pathways. Drug Alcohol Depend 1998;51:23-47.

7. Pani L, Porcella A, Gessa GL. The role of stress in the pathophysiology of the dopaminergic system. Mol Psychiatry 2000;5(1):14-21.

8. Yehuda R. Biology of post-traumatic stress disorder. J Clin Psychiatry 2000;61(7):14-21.

9. Vanlitallie TB. Stress: A risk factor for serious illness. Metabolism 2002;51(6)Suppl 1:40-50.

10. Van Dijken HH, de Goeij DC, Sutanto W, Mos J, de Kloet ER, Tilders FJ. Short inescapable stress produces long-lasting changes in the brain pituitary-adrenal axis of adult male rats. Neuroendocrinology 1993;58:57-64.

11. Servatius RJ, Ottenweller JE, Bergen MT, Soldan S, Natelson BH. Persistent stress-induced sensitization of adrenocortical and startle responses. Physiol Behav 1995;56:945-54.

12. Belda X, Fuentes S, Nadal R, Armario A. A single exposure to immobilization causes long-lasting pituitary-adrenal and behavioral sensitization to mild stressors. Horm Behav 2008;54:654-61.

13. Bugajski J, Gadek-Michalska A, Bugajski AJ. A single corticosterone pretreatment inhibits the hypothalamic-pituitaryadrenal responses to adrenergic and cholinergic stimulation. J Physiol Pharmacol 2001;52(2):313-24.

14. Gadek-Michalska A, Bugajski J. Repeated handling, restraint, or chronic crowding impair the hypothalamic-pituitary-adrenocortical response to acute restraint stress. J Physiol Pharmacol 2003;54(3):449-59.

15. Louvart H, Maccari S, Ducrocq F, Thomas P, Darnaudery M. Long-term behavioural alterations in female rats after a single intense footshock followed by situational remainders. Psychoneuroendocrinology 2005;30:316-24.
16. Armario A, Escorihuela RM, Nadal R. Long-term neuroendocrine and behavioural effects of a single exposure to stress in adult animals. Neurosci Biobehav Rev 2008;32:1121-35.

17. Güven M, Bayram F, Unlühizarci K, Keleştimur F. Endocrine changes in patients with acute organophosphate poisoning. Hum Exp Toxicol 1999;18(10):598-601.

18. Osicka-Koprowska A, Lipska M, Wysocka-Paruszewska B. Effects of chlorfenvinphos on plasma corticosterone and aldosterone levels in rats. Arch Toxicol 1984;55(1):68-9.

19. Gralewicz S, Lutz P, Kur B: Pretreatment with footshock alters some effects of subsequent organophosphate exposure. Neurotoxicology 2005;26:159-71.

20. Yanagisawa N, Morita H, Nakajima T. Sarin experiences in Japan: acute toxicity and long-term effects. J Neurol Sci 2006;249(1):76-85.

21. Yehuda R. Biology of posttraumatic stress disorder. J Clin Psychiatry 2001;62 Suppl 17:41-6.

22. Gralewicz S, Lutz P, Szymczak W. Hyposensitivity to amphetamine following exposure to chlorphenvinphos - protection by amphetamine preexposure. Acta Neurobiol Exp 2000;60:203-7.

23. Lutz P, Wiaderna D, Gralewicz S, Kur B. Exposure to chlorphenvinphos, an organophosphate insecticide, prevents from behavioral sensitization to amphetamine. Int J Occup Med Environ Health 2006;19:132-41.

24. Robinson TE, Angus AL, Becker JB. Sensitization to stress: the enduring effects of prior stress on amphetamine-induced rotational behavior. Life Sci 1985;37(11):1039-42.

25. Pacchioni AM, Gioinono G, Assis A, Cancela LM. A single exposure to restraint stress induces behavioral and neurochemical sensitization to stimulating effects of amphetamine: involvement of NMDA receptors. Ann N Y Acad Sci 2002;965: 233-46.

26. Yui K, Ikemoto S. Stress sensitization induced by stressor and methamphetamine. Jpn J Psychopharmacol 2000;24(3): 151-7.

27. Robinson TE, Berridge KC. The psychology and neurobiology of addiction: an incentive-sensitization view. Addiction 2000;95 Suppl 2:S91-117. 
28. Robinson TE, Berridge KC. Review. The incentive sensitization theory of addiction: some current issues. Philos Trans R Soc Lond B Biol Sci 2008;363(1507):3137-46.

29. Swerdlow NR, Koob GF, Cador M, Lorang M, Hauger RL. Pituitary-adrenal axis responses to acute amphetamine in the rat. Pharmacol Biochem Behav 1993;45(3):629-37.

30. Budziszewska B, Jaworska-Feil L, Lasoń W. Repeated amphetamine administration down-regulates glucocorticoid, but not mineralocorticoid, receptors in the rat hippocampus. Pol J Pharmacol 1995;47(5):401-6.

31. Adriani W, Laviola G. A unique hormonal and behavioral hyporesponsivity to both forced novelty and d-amphetamine in periadolescent mice. Neuropharmacology 2000;4;39(2): 334-46.

32. Deroche V, Marinelli M, Maccari S, Le Moal M, Simon H, Piazza PV. Stress-induced sensitization and glucocorticoids. I. Sensitization of dopamine-dependent locomotor effects of amphetamine and morphine depends on stress-induced corticosterone secretion. J Neurosci 1995;15(11):7181-8.

33. Marinelli M, Rougé-Pont F, De Jesus-Oliveira C, Le Mo al M, Piazza PV. Acute blockade of corticosterone secretion decreases the psychomotor stimulant effects of cocaine. Neuropsychopharmacology 1997;16(2):156-61.

34. Ling S, Jamali F. Effect of cannulation surgery and restraint stress on the plasma corticosterone concentration in the rat: application of an improved corticosterone hplc assay. J Pharm Pharmaceutic Sci 2003;6(2):246-51.

35. Gralewicz S, Lutz P. Behavioral sensitivity to amphetamine or scopolamine after acute administration of nicotine in the rat. Int J Occup Med Environ Health 2005;18(1):71-81.

36. Winer BJ. Statistical Principles in Experimental Design. New York: Mac Graw Hill Book Company; 1962.

37. Gralewicz S, Soćko R. Persisting behavioural and electroencephalographic effects of exposure to chlorphenvinphos, an organophosphorous pesticide, in laboratory animals. Int J Occup Med Environ Health 1997;10(4):375-94.

38. Vanderschuren LJMJ, Schmidt ED, De Vries TJ, Van Moorsel CAP, Tilders FJH, Schoffelmeer ANM. A single exposure to amphetamine is sufficient to induce long-term behavioral, neuroendocrine and neurochemical sensitization in rats. J Neurosci 1999;19:9579-86.

This work is available in Open Access model and licensed under a Creative Commons Attribution-NonCommercial 3.0 Poland License - http://creativecommons.org/ licenses/by-nc/3.0/pl/deed.en. 